\title{
Arctic Mixed-Phase Stratiform Cloud Properties from Multiple Years of Surface-Based Measurements at Two High-Latitude Locations
}

\author{
GiJs DE BOER AND EDWIN W. ElORANTA \\ University of Wisconsin-Madison, Madison, Wisconsin \\ MATTHEW D. SHUPE \\ Cooperative Institute for Research in Environmental Science, and NOAA/Earth System \\ Research Laboratory, Boulder, Colorado
}

(Manuscript received 9 December 2008, in final form 17 April 2009)

\begin{abstract}
Macro- and microphysical properties of single-layer stratiform mixed-phase clouds are derived from multiple years of lidar, radar, and radiosonde observations. Measurements were made as part of the MixedPhase Arctic Clouds Experiment (MPACE) and the Study of Environmental Arctic Change (SEARCH) in Barrow, Alaska, and Eureka, Nunavut, Canada, respectively. Single-layer mixed-phase clouds occurred between $4 \%$ and $26 \%$ of the total time observed, varying with season and location. They had mean cloud-base heights between $\sim 700$ and $2100 \mathrm{~m}$ and thicknesses between $\sim 200$ and $700 \mathrm{~m}$. Seasonal mean cloud optical depths ranged from 2.2 up. The clouds existed at temperatures of $\sim 242-271 \mathrm{~K}$ and occurred under different wind conditions, depending on season. Utilizing retrievals from a combination of lidar, radar, and microwave radiometer, mean cloud microphysical properties were derived, with mean liquid effective diameters estimated from 16 to $49 \mu \mathrm{m}$, mean liquid number densities on the order of $10^{4}-10^{5} \mathrm{~L}^{-1}$, and mean water contents estimated between 0.07 and $0.28 \mathrm{~g} \mathrm{~m}^{-3}$. Ice precipitation was shown to have mean ice effective diameters of $50-125 \mu \mathrm{m}$, mean ice number densities on the order of $10 \mathrm{~L}^{-1}$, and mean water contents estimated between 0.012 and $0.031 \mathrm{~g} \mathrm{~m}^{-3}$. Mean cloud liquid water paths ranged from 25 to $100 \mathrm{~g} \mathrm{~m}^{-2}$. All results are compared to previous studies, and potential retrieval errors are discussed. Additionally, seasonal variation in macro- and microphysical properties was highlighted. Finally, fraction of liquid water to ice mass was shown to decrease with decreasing temperature.
\end{abstract}

\section{Introduction}

The Arctic has experienced numerous long-term changes in climate variables, including rapid variation in temperature and sea ice extent. Sea ice extent has shrunk by $2.7 \%$ per decade, with larger summertime decreases (7.4\%) (Alley et al. 2007). These and other changes have had a significant impact on Arctic animals, people, and the natural environment.

Clouds exert a controlling force on the Arctic surface energy budget and atmospheric radiative fluxes (Shupe and Intrieri 2004; Pinto 1998, hereafter P98). Previous studies have shown that from late spring to midfall, lowlevel clouds to make up over half of the Arctic cloud

Corresponding author address: Gijs de Boer, Dept. of Atmospheric and Oceanic Science, University of Wisconsin-Madison, 1225 W. Dayton St., Madison, WI 53706.

E-mail: gdeboer@wisc.edu fraction (Curry and Ebert 1992). Many of these clouds are mixed-phase ${ }^{1}$ stratiform decks that persist over extended time periods (e.g., Shupe et al. 2006, hereafter S06; Rogers et al. 2001; Curry et al. 1996). Ice formed in the mixed-phase layer grows and precipitates out. Supercooled liquid contained in these clouds increases surface longwave flux, with Curry et al. (1996) estimating wintertime reductions in net radiative surface cooling by $40-50 \mathrm{~W} \mathrm{~m}^{-2}$. This affects sea ice extent, permafrost depths, and vegetation growth.

Recently completed modeling studies (Klein et al. 2009; Morrison et al. 2009) reveal that even state-of-the-science

\footnotetext{
1 "Mixed phase" is defined as a region sampled at the vertical resolution of the utilized instruments, containing both a liquid cloud layer and ice particles. Frozen precipitation below cloud base is not included. Cloud base is located at the lowest altitude (again, sampling resolution limited) containing liquid water.
} 


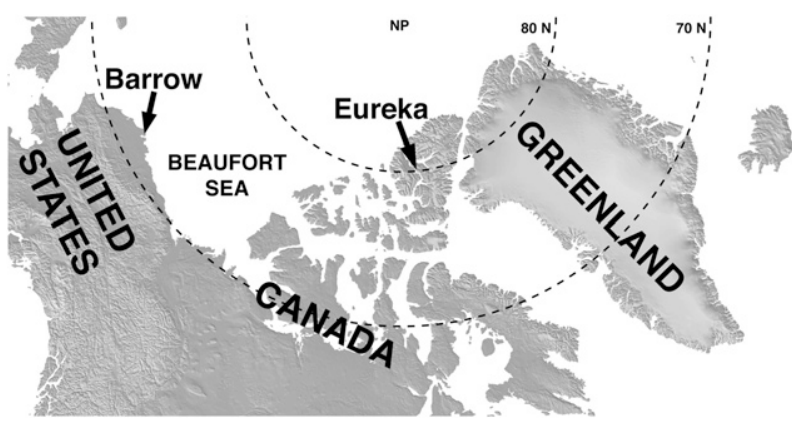

FIG. 1. A map of the western Arctic indicating the locations of the MPACE (Barrow) and SEARCH (Eureka) campaigns [from USDOC/NOAA/NESDIS National Geophysical Data Center (NGDC), edited].

numerical models have difficulty replicating the delicate balance between liquid and ice in these clouds. This is due in part to poor representation of mixed-phase microphysics in model parameterizations, stemming in part from difficulties with accurate prediction of ice nucleation. Excessive nucleation leads to excessive ice depositional growth, rapidly depleting cloud liquid through the BergeronFindeissen process (Pruppacher and Klett 1997), while insufficient nucleation results in a thick liquid layer that is not representative of the observed mixed-phase state.

Unfortunately, there are few long-term observational datasets from high-latitude locations focused on mixedphase clouds. The Surface Heat Budget of the Arctic Ocean (SHEBA; Uttal et al. 2002) and Mixed-Phase Arctic Clouds Experiment (MPACE; Verlinde et al. 2007) are recent examples of campaigns aimed specifically at obtaining information on high-latitude clouds. MPACE took place at the Department of Energy (DOE) Atmospheric Radiation Measurement (ARM) climate research facility on the North Slope of Alaska. Although MPACE was significantly shorter than the year-long SHEBA experiment ( $\sim 2$ months in the fall of 2004$)$, it was focused specifically on mixed-phase cloud processes. In addition to these focused observational periods, the Study of Environmental Arctic Change (SEARCH; Morison 2001) is an ongoing effort aimed at tracking environmental change in the Arctic through long-term observation. Through SEARCH, the National Atmospheric and Oceanographic Administration (NOAA) has collaborated with the Canadian Network for the Detection of Atmospheric Change (CANDAC) to provide continuous measurements of atmospheric properties at Eureka, Nunavut, Canada, since August of 2005.

This study utilizes multiple remote sensors to derive a multiyear dataset that includes observation from both MPACE and SEARCH (Fig. 1). Basic macrophysical quantities such as cloud-base and -top heights, cloud thickness, cloud optical depth (OD), and cloud frequency are presented. In addition, observed cloud temperatures, wind directions, and microphysical data for both mixedphase and subcloud regions are provided.

Quantities provided, as described above, are designed to complement those presented in previous studies (e.g., S06; Shupe et al 2008a, hereafter S08a; P98; Zuidema et al. 2005, hereafter Z05). Combined assessment of these datasets provides information on Arctic mixedphase clouds, including spatial and seasonal variations. The goal of this work is to provide information for improvement of model parameterizations and observational techniques that will aid in improvement of estimates of Arctic climate change.

\section{Overview of measurements and methods}

\section{a. Instrumentation}

This study is based on information from multiple instruments. The University of Wisconsin Arctic High Spectral Resolution Lidar (AHSRL; Eloranta 2005) provides calibrated profiles of backscatter cross section, particle depolarization ratio, and optical depth at a wavelength of $532 \mathrm{~nm}$. In addition to the AHSRL, radar reflectivity profiles from a $35-\mathrm{GHz}(8-\mathrm{mm})$ Millimeter Cloud Radar (MMCR; Moran et al. 1998) were utilized. For both deployments, the AHSRL and MMCR were collocated, and sampling occurred with only a few meters separating instruments.

Because the AHSRL and MMCR operate at very different wavelengths, they respond to different hydrometeor properties. The AHSRL is sensitive to the crosssectional area of sampled particles. Therefore, regardless of size, high numbers of particles (i.e., liquid cloud) cause a high backscatter cross section. The MMCR is sensitive to particle volume squared, and therefore it is very sensitive to large particles, which in mixed-phase clouds are typically ice crystals. These contrasting wavelengths complement each other nicely in measuring a mixedphase environment. The AHSRL also provides a measurement of depolarization ratio. Spherical particles such as liquid droplets result in low depolarization ratios, whereas nonspherical particles such as ice crystals produce higher depolarization ratios. Data from an onsite microwave radiometer (MWR) and twice-daily radiosonde launches from Barrow and Eureka weather stations are also utilized.

Figure 2 shows combined monthly uptime statistics for the two primary instruments. Because microphysical and cloud-boundary estimates could only be made for cases when both instruments were operating, cases in which one of the two was not operating were removed for this study. Although most months had instrument uptimes of $80 \%$ or better, there are some clear exceptions. Most 


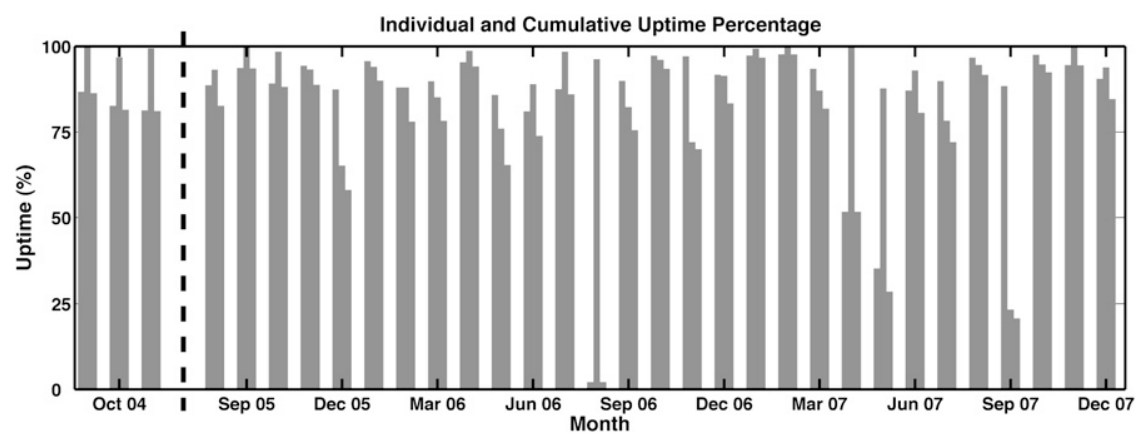

FIG. 2. Monthly statistics of AHSRL (left bar), MMCR (center bar), and combined (right bar) instrument activity (uptime) from Barrow (left of the dashed line) and Eureka for each month of operation.

notably, August 2006 had a combined uptime of only $3 \%$. There may be a slight bias in seasonal statistics for cloud occurrence because of these lapses in data.

\section{b. Identification of cases}

AHSRL and MMCR data from MPACE and SEARCH were manually reviewed for cases featuring single-layer mixed-phase stratus. Regions were identified as mixedphase clouds when they contained a high AHSRLmeasured backscatter cross section and low depolarization while simultaneously having a measured radar reflectivity at the same altitude and high depolarization ratios below cloud base (Fig. 3). In addition, cloud structure was considered: only stratiform clouds (i.e., thin vertically, and continuous in nature as in Fig. 3) were included. Any half-hour occurrence of mixed-phase stratiform clouds was considered to be a case. Cases showing additional cloud layers in either lidar or radar data within $1 \mathrm{~km}$ (vertically) of the stratiform layer were discarded. This subsetting was done to focus on single-layer clouds and to ensure removal of any seeding effects provided by nearby clouds.

\section{c. Estimation of macrophysical properties}

The first distinction made for each case was between the mixed-phase layer and frozen precipitation that occurs below it. To accomplish this, cloud base was determined from AHSRL backscatter cross section and depolarization measurements. Areas with backscatter cross sections greater than $5 \times 10^{-5} \mathrm{~m}^{-1} \mathrm{sr}^{-1}$ and depolarization below 0.03 were determined to contain liquid. These threshold values were chosen through trial and error for cases from this dataset. The first such point from the surface was determined to be cloud base for each 15-s averaging interval. Any signal below cloud base was classified as precipitation.

Cloud top is more difficult to determine because of possible AHSRL attenuation within the cloud layer.
Lidar backscatter cross section was utilized for cases with optical depths below one. For cases with optical depths greater than one, radar reflectivity was used. Because the radar is most sensitive to larger ice crystals and likely misses small liquid droplets near cloud top, a question to address is whether the uppermost radar returns are indicative of cloud top. In situ measurements from MPACE (McFarquhar et al. 2007, hereafter M07) indicate that ice indeed extends throughout the mixedphase layer to cloud top. Additionally, radar-estimated cloud-top heights were compared with those calculated from the Cloud-Aerosol Lidar with Orthogonal Polarization (CALIOP) on the Cloud-Aerosol Lidar and Infrared Pathfinder Satellite Observation (CALIPSO) satellite for two overpasses that occurred within $1 \mathrm{~km}$ from Eureka. Both cases resulted in discrepancies smaller than $30 \mathrm{~m}$, the resolution of the CALIOP instrument.

\section{d. Cloud temperature and wind profiles}

In instances where radiosonde launches occurred during an observed mixed-phase case, estimates of temperature and wind are available. Cloud boundaries are averaged over \pm 15 min from launch time to assure representative cloud properties during a radiosonde profile. By combining these average cloud boundaries and radiosonde profiles, cloud top, cloud base, and cloud minimum and maximum temperatures are assigned. Additionally, in-cloud wind speeds and directions are estimated.

\section{e. Estimation of microphysical properties}

In addition to estimates of macrophysical properties, microphysical information is retrieved using a modified version of algorithms introduced by Donovan and van Lammeren (2001). From a combination of lidar and radar backscatter cross sections, particle effective size, particle number density, and water content are derived. Use of the AHSRL in this application has several advantages. 

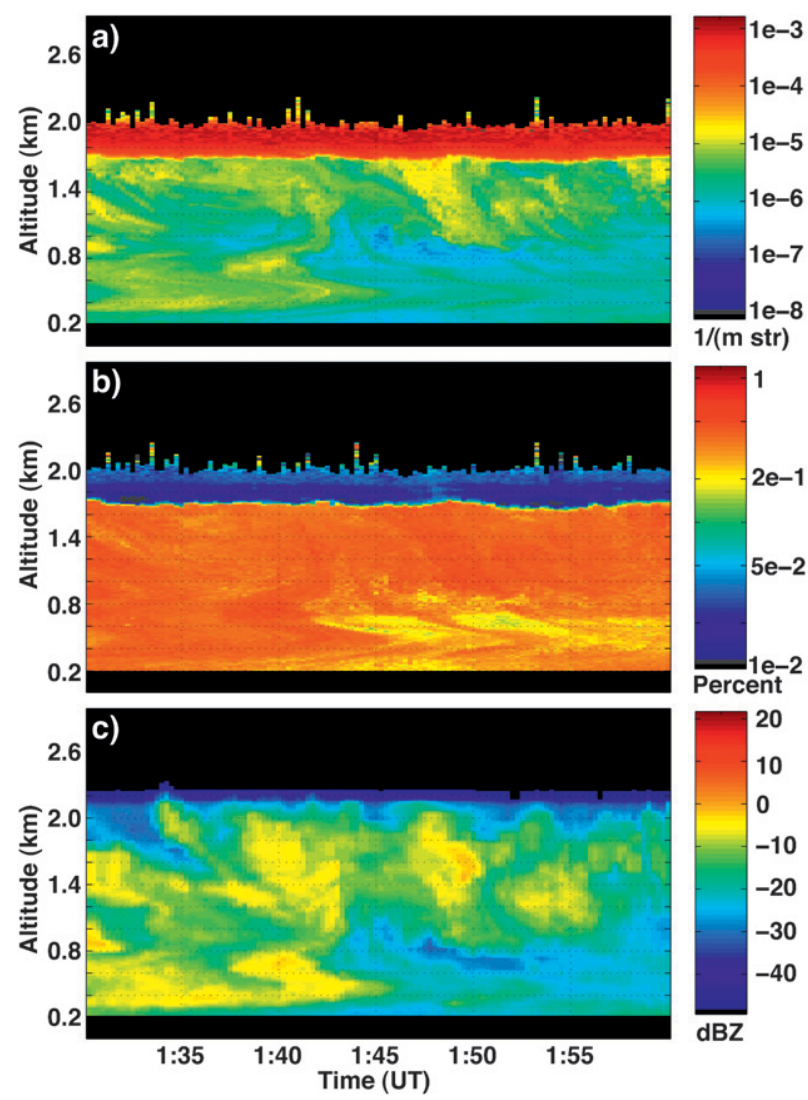

Percent
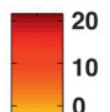

0

$-10$

$-20$

$-30$

$-40$

$\overline{d B Z}$

FIG. 3. A typical 30-min single-layer mixed-phase stratus case as observed in (a) AHSRL backscatter cross section, (b) AHSRL depolarization, and (c) MMCR reflectivity on 29 Dec 2006. The liquid portion of the mixed-phase cloud results in high backscatter cross section and low depolarization at $\sim 1800 \mathrm{~m}$ and above. Note that for this case the lidar is attenuated before reaching the top of the layer.

First, AHSRL measurements are calibrated, meaning a priori assumptions about attenuation are not required. Second, although these retrievals are limited to portions of clouds in which the lidar signal is not attenuated, the AHSRL design allows penetration to optical depths near 5 , allowing for deeper penetration into clouds than that provided by most other lidar systems. In short, the ratio of radar backscatter cross section to that of the lidar results in an expression that can be solved for effective diameter, where effective diameter is defined as

$$
D_{\text {eff }}=\frac{3 \bar{V}}{2 \bar{A}}
$$

where $\bar{V}$ is the average volume of particles within the sampled volume and $\bar{A}$ is the average particle crosssectional area.

Using this technique, assumptions are required about the particle size distribution and particle shape. We assume a modified gamma distribution (Deirmendjian 1969):

$$
n(D)=a D^{\alpha} \exp \left(-b D^{\gamma}\right)
$$

where $D$ is the maximum particle dimension, $n$ is the number of particles per unit volume per unit length, and $a, b, \alpha$, and $\gamma$ are size distribution parameters. Additionally, power-law relationships are assumed for particle volume and area. These relationships were modified slightly from those presented by Mitchell (1996) in order to have nondimensional coefficients:

$$
\begin{aligned}
& V=\sigma_{v} \frac{\pi}{6} D_{r}^{3-\delta_{v}} D^{\delta_{v}}, \\
& A=\sigma_{a} \frac{\pi}{4} D_{r}^{2-\delta_{a}} D^{\delta_{a}},
\end{aligned}
$$

where $V$ and $A$ are the volume and area of a particle, respectively; $D_{r}$ is a habit-dependent reference diameter; and $D$ is the maximum dimension of the particle. Here, $\sigma_{v}$ and $\sigma_{a}$ are the filled fraction of the volume and projected area, respectively, of a sphere with a diameter $D_{r}$. For spherical particles, $\sigma_{v}=1, \delta_{v}=3, \sigma_{a}=1$, and $\delta_{a}=2$. Values of these parameters were outlined for varying particle shapes by Mitchell (1996). Because a combined distribution of liquid and ice particles is bimodal, a single gamma distribution cannot be used to represent both phases. In principle, for this retrieval method separate gamma distributions for liquid and ice could be utilized, assuming contributions of each phase to measured signals could be separated. Unfortunately, this is currently not possible, and therefore any sampled volume is assumed to consist of either water or ice. Naturally, this assumption fails in mixed-phase cloud volumes; therefore, microphysical estimates from this region should be analyzed with caution. For areas assumed to be ice, "graupel" is assumed as the particle type for reasons discussed in de Boer et al. (2008).

With an estimate of particle size, number density and total water content (TWC) can also be retrieved from the lidar-radar combination. In addition, a radar-only estimate of ice water content (IWC) is included. This retrieval is based on a simple reflectivity-IWC relationship:

$$
\mathrm{IWC}=a Z_{e}^{b},
$$

where $a$ and $b$ are fixed coefficients and $Z_{e}$ is the radar reflectivity. These coefficients have been determined for clouds from SHEBA measurements, with $a=0.07$ (Shupe et al. 2005) and $b=0.63$ (Matrosov 1999). Unlike combined lidar-radar retrievals, this estimate is strongly indicative of IWC because larger particles strongly dominate the radar signal.

Finally, microwave radiometer retrievals of cloud liquid water path (LWP) are performed based on the 
two-stage process outlined by Turner et al. (2007). First, statistical retrievals are run relating observed downwelling radiation at approximately 23 and $30-31 \mathrm{GHz}$ to LWP and precipitable water vapor using site-specific monthly retrieval coefficients derived from historic radiosonde data. These retrievals are then constrained using more accurate physical microwave retrievals that can only be performed when radiosonde temperature profiles are available (approximately twice per day). An MWR was not installed at Eureka until summer 2006, and it was inoperative during much of November and December 2007. All data represented in the MWR analysis were also included in the lidar-radar analysis; however, the opposite is not true.

\section{f. Discussion on sources of microphysical retrieval error}

As outlined in Shupe et al. (2008b), the most challenging aspect of ground-based microphysical retrievals in mixed-phase clouds is correct characterization of liquid. The lidar-radar retrieval implemented here assumes only a monomodal size distribution and is thus unable to accurately portray a mixed-phase size distribution. This limitation results in one of two situations. The first is to assume a liquid-only sampling volume despite large radar reflectivities, resulting in estimated liquid particle sizes that are too large and number densities that are too small. Conversely, if the phase is assumed to be ice, a severe overestimation of ice number density and underestimation of size results because of large lidar-measured backscatter cross sections.

Comparisons between retrieved microphysical estimates using the above techniques and in situ measurements from aircraft measurements over Barrow during MPACE were presented in de Boer et al. (2008). Because of lidar attenuation, there was limited overlap between retrievals and aircraft data within liquid-containing layers. Comparisons showed that lidar-radar retrievals overestimated liquid droplet size by approximately a factor of 2 due largely to the volume-squared contribution from radar-detected ice. Particle number density was underestimated by almost an order of magnitude $\left(10^{4}\right.$ versus $10^{5} \mathrm{~L}^{-1}$ ) because particle size is utilized in particle area estimation. Water content was also overestimated by approximately a factor of 2 , again because of utilization of particle size and area in the calculation. These errors become smaller with a reduced ice amount. The following sections show significantly less ice in Eureka clouds when compared to those used in the above comparison, and therefore liquid retrieval errors are expected to be less than those outlined above.

When looking at subcloud ice, assumed particle shape is the largest source for potential error. The assumed

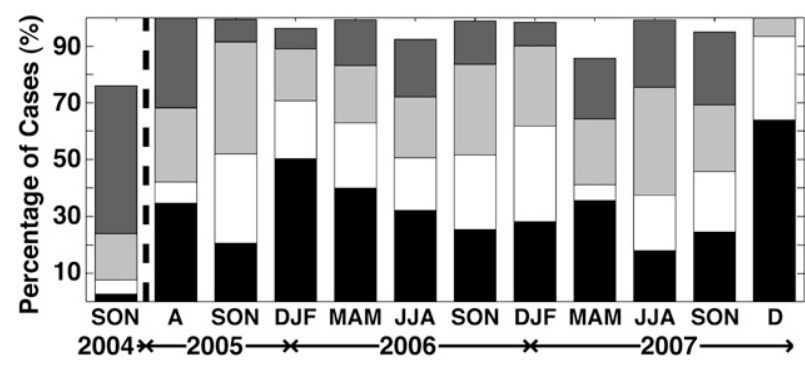

FIG. 4. A bar graph showing the percentage of all cases (by season) in which the lidar observed $80 \%$ or more (black), $60 \%$ or more (white), $40 \%$ or more (light gray), and $20 \%$ or more (dark gray) of the total cloud depth.

graupel crystal type resulted in the best agreement when compared with in situ ice measurements from MPACE, with differences in mean particle size of $<50 \%$, mean number densities that were both on the order of $1-10 \mathrm{~L}^{-1}$, and TWC generally ranging between 0 and $0.1 \mathrm{~g} \mathrm{~m}^{-3}$. For that particular dataset, variation of assumed particle shape resulted in effective diameter changes of up to $200 \mu \mathrm{m}$, number density of up to $90 \mathrm{~L}^{-1}$, and TWC of up to $0.011 \mathrm{~g} \mathrm{~m}^{-3}$. Although some of these numbers may seem large, they are significantly reduced when only applying particle shapes resembling the irregularly shaped crystals with significant riming that have been observed in these clouds (M07; Korolev et al. 1999).

An additional source of error is full lidar signal extinction below cloud top for clouds with optical depths greater than 5 . Thus, combined retrievals for thicker clouds do not include the upper portion of the cloud, where LWC is typically highest, introducing a bias toward underestimated cloud-mean LWC. Figure 4 illustrates the extent of attenuation on the collected dataset. The bars illustrate the percentage of cases, by season, for which the lidar was able to sample $80 \%$ or more (black), $60 \%$ or more (white), $40 \%$ or more (light gray), and $20 \%$ or more (dark gray) of physical cloud depth. Most clouds featured some effects due to attenuation. Winter typically had the least amount of cloud missed due to attenuation, whereas summer and fall had the largest amounts. As discussed later, Barrow clouds were significantly thicker than those at Eureka, resulting in lidar penetration of less than $40 \%$ of the cloud vertical extent $75 \%$ of the time. In contrast, Eureka clouds featured at least $40 \%$ vertical sampling between $61 \%$ and $100 \%$ of the time, depending on season.

In summary, it is expected that for mixed-phase volumes, estimates of liquid droplet sizes are too large, number densities are too small, and water contents are too high. Lidar attenuation is significant in the data and its impact will be discussed when appropriate in the results section. 


\section{Results}

Statistics presented here are for single-layer mixedphase stratiform clouds observed at Barrow and Eureka. Each data point represents a half-hour (case) average. In total, there were 532 data points from MPACE and 2478 data points from SEARCH measurements. Combined, this dataset represents over $1500 \mathrm{~h}$ of single-layer mixed-phase cloud observations. Because statistics on temperature and wind required a nearly coincident radiosonde launch, these datasets are reduced significantly in size (13 for Barrow and 110 for Eureka). Box-andwhisker plots illustrate the median (box center), 25th and 75 th percentiles [interquartile range (IQR), box edges), and 5th and 95th percentiles (whisker ends) for the given season. Additionally, all values in the outer $10 \%$ of the data are represented by ovals. Seasonal mean values discussed in this work exclude outliers $(>2 \times \mathrm{IQR}$ outside of IQR) and are shown using asterisks.

\section{a. Cloud occurrence and macrophysical properties}

Figure 5a illustrates frequency of occurrence of singlelayer, mixed-phase clouds for each season covered by the data. This value was calculated as the number of halfhour cases found in the season (number at the bottom of each bar) divided by the total number of half-hour time periods during which the radar and lidar were operating simultaneously (shown in Fig. 2). The MPACE period of September-November (SON) 2004 shows a significantly higher frequency of occurrence $(\sim 26 \%)$ than any season observed at Eureka. This difference is not surprising since the Beaufort Sea (north of Barrow) is open during the fall season, providing a significant atmospheric moisture source, as well as vertical motions forced by the relatively warm water surface. Without exclusion of multilayered cases, the frequency of mixed-phase cloud occurrence is even higher than represented here.

At Eureka, fall also seems to have a more frequent occurrence of single-layer mixed-phase clouds (10\%-15\%). Interestingly, spring does have far fewer cases than other seasons (typically $<5 \%$ ). During summer and winter, frequencies also decrease from those observed during fall (5\%-8\% and 5\%-12\%, respectively). Although clouds are still present, more are entirely liquid during the summertime and entirely glaciated during winter.

Figure $5 \mathrm{~b}$ compares cloud-base heights (base of cloud liquid) for different seasons. Interestingly, cloud-base height appears to show an annual cycle, with heights in fall and spring being lower (means $<1500 \mathrm{~m}$ ) than those detected during summer months (means $>2000 \mathrm{~m}$ ). This makes intuitive sense because colder temperatures necessary for mixed-phase cloud maintenance are found at higher altitudes during summer months. Interestingly,

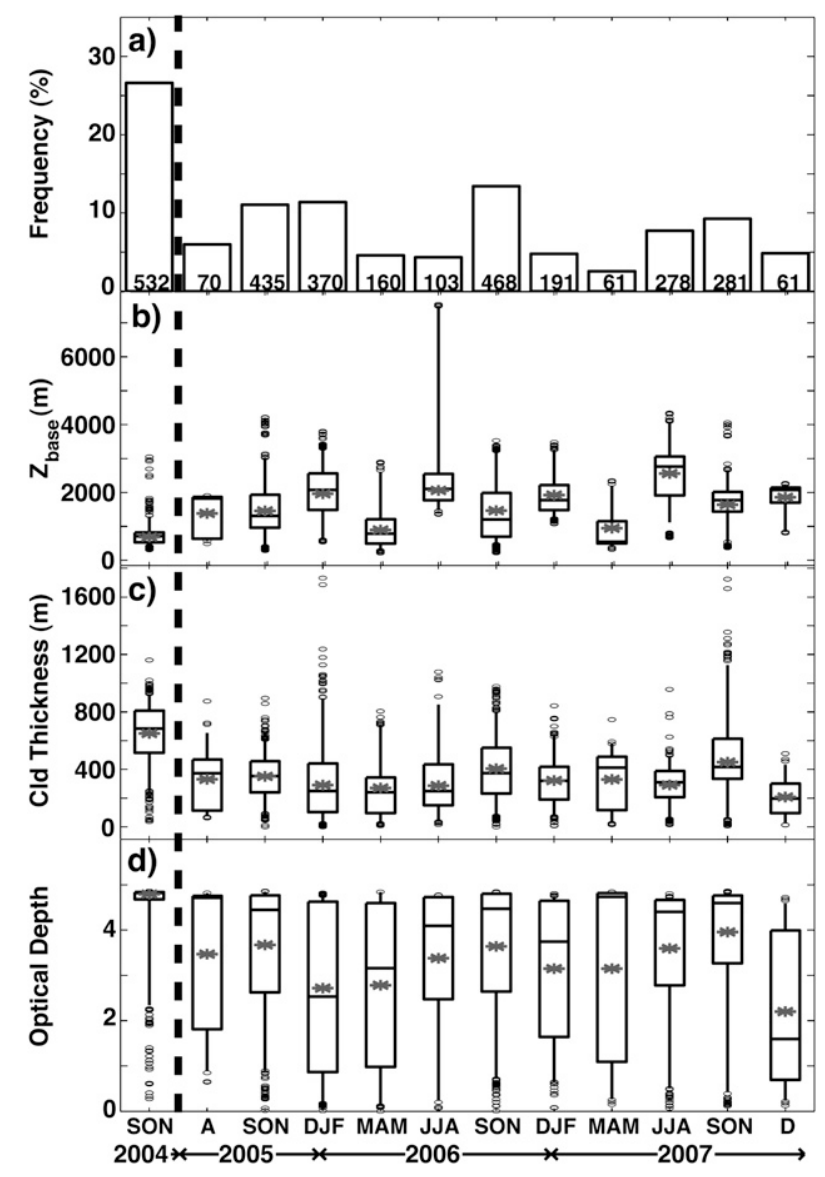

FIG. 5. Seasonal statistics for single-layer, stratiform clouds, as observed at Barrow (2004) and Eureka (2005-07). Indicated are (a) frequency of occurrence, (b) mean cloud-base height, (c) mean cloud thickness, and (d) mean lidar-measured cloud optical depth. The box-and-whisker plots provide the 5th, 25th, 50th, 75th, and 95th percentiles of the 30 -min averages, as well as the mean (asterisk) and outer $10 \%$ of the data (ovals).

base heights associated with winter months (means $\sim=2000 \mathrm{~m}$ ) increase from those observed during transition seasons.

Figure $5 \mathrm{c}$ compares cloud thicknesses for different seasons. Seasonal mean thicknesses range from around 200 to $700 \mathrm{~m}$, with the thinnest clouds being only tens of meters thick and the thickest around $1000 \mathrm{~m}$ thick on average. The thickest clouds exist during fall and the thinnest during spring. Barrow observations show substantially thicker clouds, on average, than those observed in Eureka.

Thirty-minute average lidar cloud optical depths are reviewed in Fig. 5d. These statistics are skewed by the AHSRL's inability to penetrate deeper than an optical depth of around 5 before suffering from attenuation. As shown in Fig. 4, a large fraction of these clouds are thicker than this. Despite this, there are annual patterns 


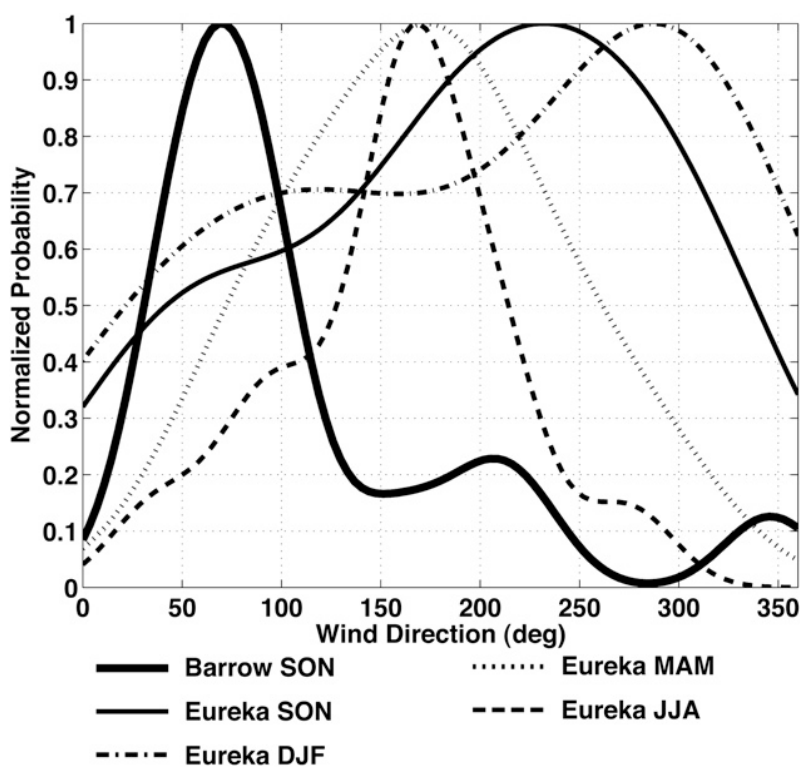

FIG. 6. Normalized probability density functions of wind direction during single layer mixed-phase cloud cases, separated by season and location.

in the optical depth data. Winter months feature clouds with the lowest optical depths (mean OD $\sim 2-3$ ), whereas fall and summer months typically produce the thickest clouds (mean OD $\sim 3+$ ). Again, Barrow clouds are optically thicker than those at Eureka.

\section{b. Temperature and wind conditions}

To better understand dynamic and thermodynamic atmospheric states that support development and maintenance of these single-layer clouds, temperature and wind information from radiosonde launches was analyzed. Figure 6 shows observed in-cloud wind direction for the cloud cases. At Barrow, winds are predominantly from the east and northeast. At Eureka, the predominant wind direction supporting mixed-phase clouds varies significantly with season. During fall, cloud-level winds are generally from the southeast. During winter, the distribution flattens out somewhat, illustrating less of a dependence on wind direction. Spring and summer months favor mixed-phase cloud formation under southsoutheasterly winds.

Figure 7 illustrates statistics of mean cloud minimum temperatures observed for periods with mixed-phase cloud layers. The observed temperature range covers values between 242 and $271 \mathrm{~K}$. Warmer temperatures were observed during summer (mean $\sim 263-268 \mathrm{~K}$ ), with the coldest temperatures observed during winter (mean $\sim 245 \mathrm{~K}$ ). Transition seasons [March-May (MAM) and $\mathrm{SON}$ ] observed both at Eureka and Barrow generally featured temperatures between $\sim 250 \mathrm{~K}$ and $260 \mathrm{~K}$. June,

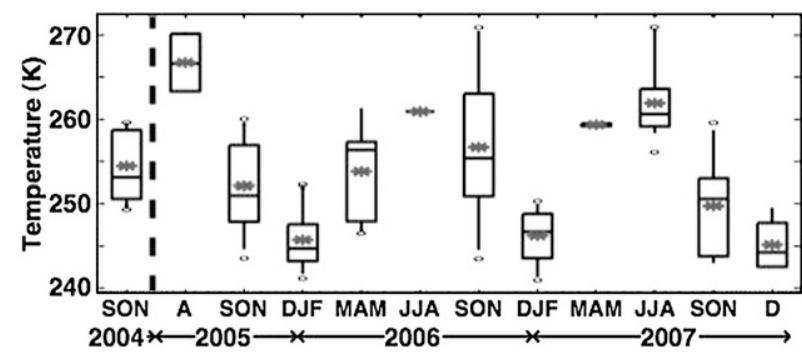

FIG. 7. Seasonal statistics of cloud minimum temperature for single-layer mixed-phase clouds as observed at Barrow (2004) and Eureka (2005-07). Statistics were gathered solely for clouds observed within $15 \mathrm{~min}$ of a radiosonde launch. The box-and-whisker plots are as in Fig. 5.

July, and August (JJA) 2006 and MAM 2007 had few cases during radiosonde launches.

\section{c. Microphysical properties}

Estimates of microphysical properties are divided into those retrieved from two separate regions: those from the mixed-phase layer as observed by lidar and those from subcloud precipitation. Based on AHSRL depolarization measurements, precipitation is assumed to consist only of frozen hydrometeors. In-cloud lidar-radar size and number density retrievals are assumed to be representative of liquid due to the strong influence of the liquid droplets on the lidar backscatter cross section. Radar-only ice retrievals are available for both regions.

Figure 8 shows seasonal statistics for in-cloud microphysical retrievals. The top three panels showing cloud liquid properties are most representative of lower parts of the cloud since the lidar frequently suffers from signal occultation, as shown in Fig. 4. It is expected that drop size and LWC increase with height in the cloud (i.e., M07), and thus layer-averaged values may be larger than those shown here. For Eureka data, mean cloud droplet effective diameters are around $20 \mu \mathrm{m}$ (Fig. 8a), with slightly lower values and less variation during summer, and slightly higher values and increased variation during transition seasons (SON, MAM). Barrow data feature much larger effective diameter estimates, with a mean of means around $50 \mu \mathrm{m}$. Because of higher radar reflectivities associated with this data, larger particles size estimates are likely due to an increase in the amount of ice contamination on the retrieval rather than an actual increase in droplet size of the extent shown.

Some indications of an annual cycle are evident in Eureka in-cloud mean particle number densities (Fig. 8b), with estimates from summer months exceeding $10^{5} \mathrm{~L}^{-1}$ and wintertime estimates closer to $5 \times 10^{4} \mathrm{~L}^{-1}$. Notable exceptions to the seasonal cycle include MAM 2007 and SON 2006. Barrow number densities are generally lower, with the majority of data points falling below $5 \times 10^{4} \mathrm{~L}^{-1}$. 


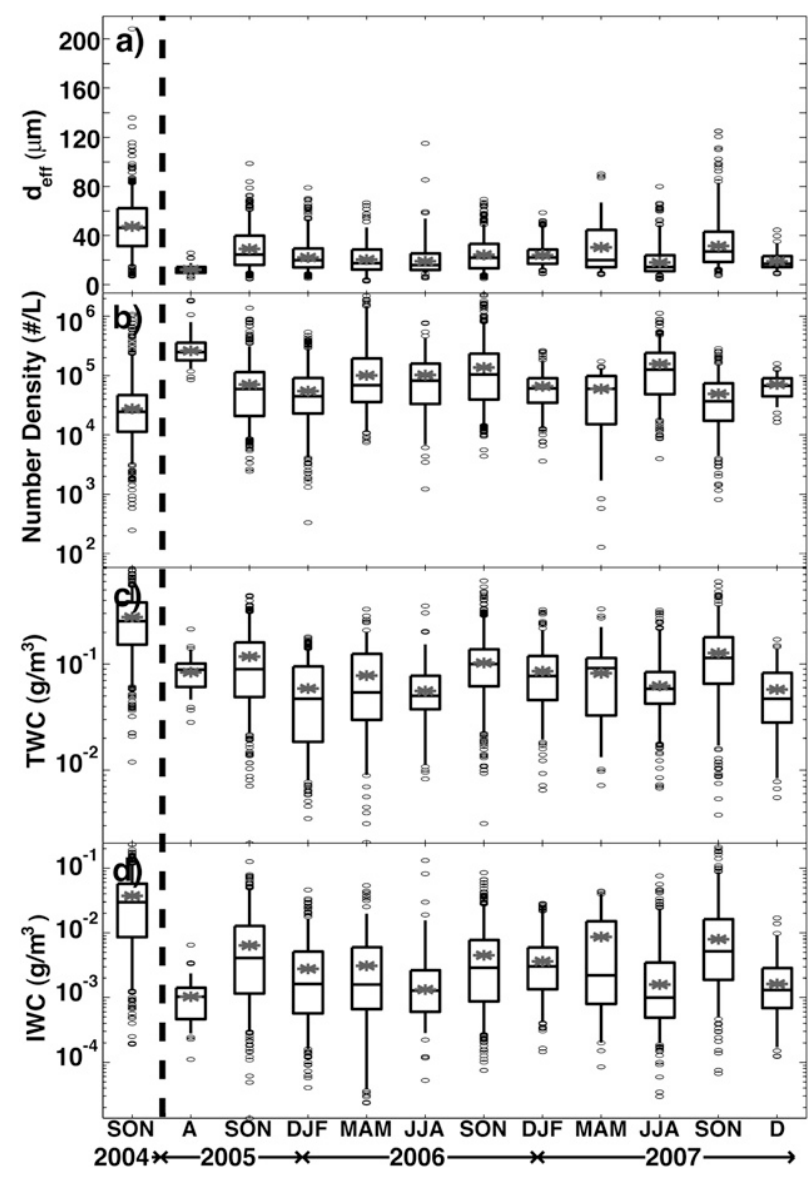

FIG. 8. Seasonal statistics for the retrieved microphysical characteristics of single-layer, stratiform mixed-phase clouds, as observed at Barrow (2004) and Eureka (2005-07). These values are for the region containing both liquid and ice and, with the exception of IWC, are indicative of liquid properties. Indicated are (a) lidar-radar-derived estimates of mean liquid effective diameter, (b) mean liquid droplet number density, (c) mean total water content, and (d) a radar-only estimate of mean ice water content. The box-and-whisker plots are as in Fig. 5.

All seasons reveal a relatively large spread in retrieval estimates, covering one or more orders of magnitude.

Statistics from the lidar-radar TWC retrieval are shown in Fig. 8c. An annual cycle also appears in this data, with higher TWC during fall, a decrease into winter, and then a slight increase into spring. Interestingly, the summer months do not seem to continue this trend, with all three summer seasons featuring lower TWC. The annual mean value from Eureka is approximately $0.1 \mathrm{~g} \mathrm{~m}^{-3}$, with fall typically closer to $0.15 \mathrm{~g} \mathrm{~m}^{-3}$ and summer closer to $0.05 \mathrm{~g} \mathrm{~m}^{-3}$. Cases observed in Barrow feature higher TWC, with a mean near $0.3 \mathrm{~g} \mathrm{~m}^{-3}$. With a significant portion of Barrow clouds missed due to attenuation, this is likely an underestimate. For both locations, the spread in case means is highest during fall.
In-cloud, radar-only mean IWC is presented in Fig. 8d. IWC follows a trend similar to that of TWC. SON typically has the highest values, with mean IWC between 0.005 and $0.008 \mathrm{~g} \mathrm{~m}^{-3}$. Summer is again the lowest, with mean values of approximately $0.001 \mathrm{~g} \mathrm{~m}^{-3}$. Data collected at Barrow feature higher IWC than those from Eureka, with a mean value of $0.037 \mathrm{~g} \mathrm{~m}^{-3}$ and a wide distribution extending between $\sim 0$ and $0.1 \mathrm{~g} \mathrm{~m}^{-3}$.

Microphysical information on frozen precipitation below cloud base is reviewed in Fig. 9. Effective diameter estimates are naturally much higher for ice than for in-cloud liquid, with mean values typically between 50 and $120 \mu \mathrm{m}$. Differences between months fall within the range of uncertainty in estimating the particle size, and therefore no significant seasonal trend is observed in the data. Ice particles observed in Barrow appear to be larger than those observed in Eureka, with the mean case average falling around $125 \mu \mathrm{m}$.

Because of large differences in particle concentrations between in-cloud and subcloud regions, even a minor miscalculation of cloud-base height has significant impacts on number density statistics (Fig. 9b). These miscalculations lead to some large outlying values. For both Barrow and Eureka, mean values for case-mean particle number density fall around $10 \mathrm{~L}^{-1}$. The interquartile ranges for this dataset typically range from around $1 \mathrm{~L}^{-1}$ to approximately $30 \mathrm{~L}^{-1}$.

Without the presence of cloud liquid, below-cloud TWC (Fig. 9c) is much smaller than in-cloud TWC (Fig. 8c). Additionally, lidar-radar TWC estimates are very similar in magnitude to radar-only IWC estimates (Fig. 9d), with lidar-radar estimates being slightly lower. Both sets of values range from approximately 0.0001 to $0.05 \mathrm{~g} \mathrm{~m}^{-3}$, with outliers extending to around $0.15 \mathrm{~g} \mathrm{~m}^{-3}$. Also, radaronly IWC estimates below cloud are slightly larger than those in cloud.

Finally, liquid water paths from the MWR dataset are reviewed in Fig. 10. LWPs were largest in fall, with mean values for Eureka ranging from around $50 \mathrm{~g} \mathrm{~m}^{-2}$ during fall to only around $25 \mathrm{~g} \mathrm{~m}^{-2}$ during winter. Fall also had the largest variation in estimated LWP, with IQRs of $15-80 \mathrm{~g} \mathrm{~m}^{-2}$ (as opposed to a winter IQR of 7-28 $\mathrm{g} \mathrm{m}^{-2}$ ). Barrow featured significantly larger LWPs, with a mean of approximately $100 \mathrm{~g} \mathrm{~m}^{-2}$ and an IQR of 43 to $150 \mathrm{~g} \mathrm{~m}^{-2}$.

\section{Discussion}

\section{a. Comparison with previous observations and insight into results}

Although this study constitutes one of the longest observation periods for this type of cloud, previous analysis of mixed-phase stratiform cloud properties has been done through observations of various shorter time 

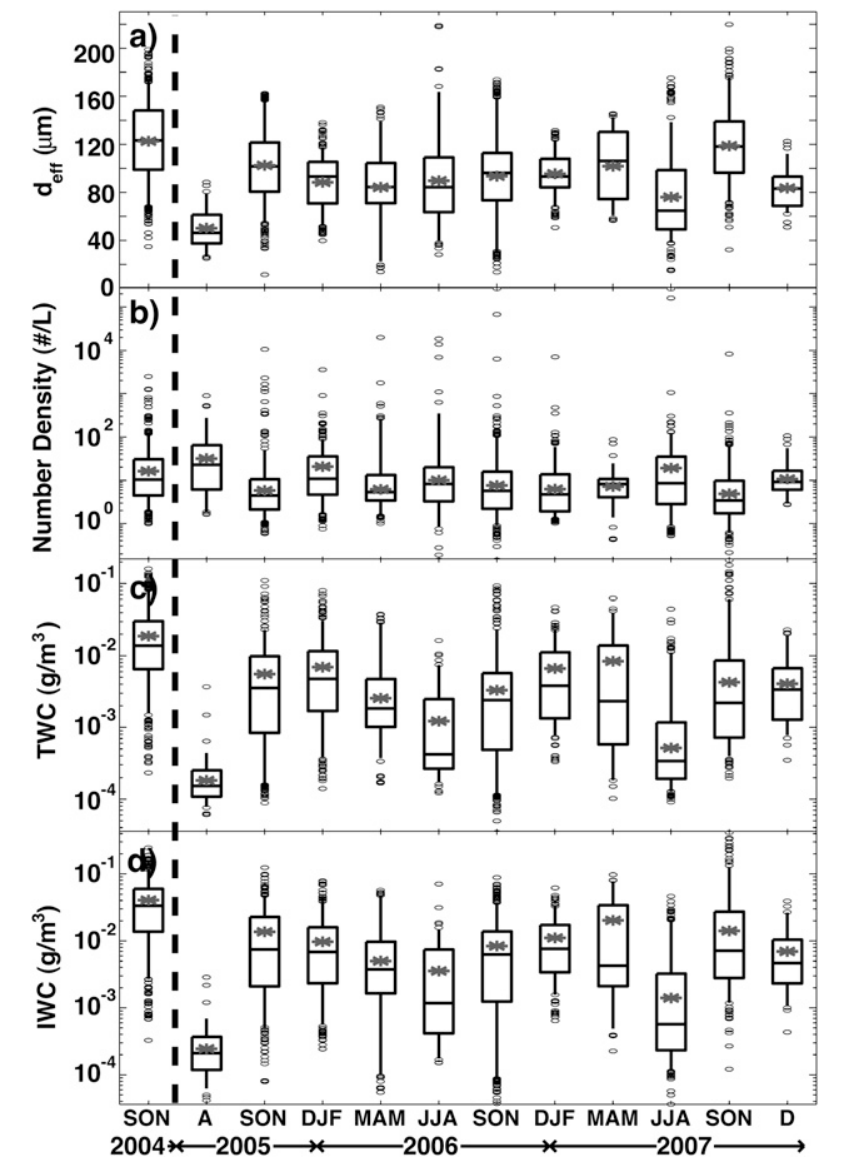

FIG. 9. Seasonal statistics for the retrieved microphysical characteristics of frozen precipitation falling from single-layer mixedphase clouds, as observed at Barrow (2004) and Eureka (2005-07). These values are for the subcloud region containing only ice and are indicative of ice properties. Indicated are (a)-(c) lidar-radarderived estimates of (a) mean effective diameter, (b) mean particle number density, and (c) mean total water content (c), as well as (d) a radar-only estimate of mean ice water content. The box-andwhisker plots are as in Fig. 5.

scales. S08a describe mixed-phase clouds observed during MPACE. In addition, S06 review findings from $1 \mathrm{yr}$ of observations during SHEBA, whereas Turner (2005, hereafter referred to as T05) and Z05 review 7-month and week-long mixed-phase stratus properties, respectively, also from SHEBA. In addition, M07 present aircraft and ground-based measurements from MPACE. Finally, P98 presents data from the 1984 Beaufort and Arctic Storms Experiment (BASE).

Generally, comparisons to these datasets result in agreement on cloud properties. Comparing mixed-phase cloud occurrence with S06, the current study appears to have substantially lower numbers (a seasonally dependent $5 \%-25 \%$ versus $10 \%-70 \%$ in S06). However, S06 was not limited to single-layer or stratiform mixed-phase clouds as in the current work.

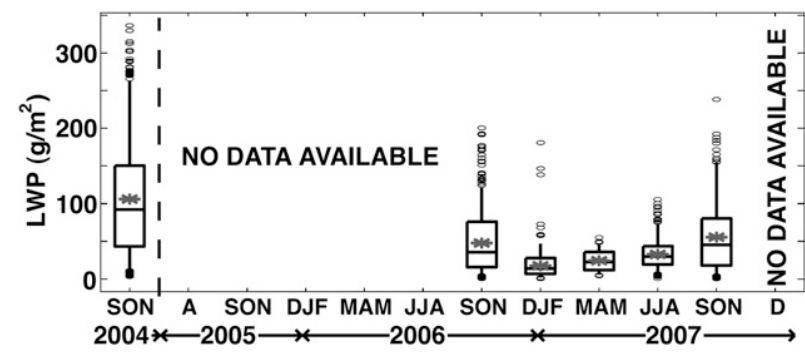

FIG. 10. Seasonal statistics for microwave radiometer retrieved LWPs of single-layer mixed-phase clouds, as observed at Barrow (2004) and Eureka (2005-07). The box-and-whisker plots are as in Fig. 5.

Cloud-base heights derived here (mean 680-2600 m) agree well with those derived in S08a (500-800 m), S06 (200-2500 m), M07 (400-800 m), P98 (400-1100 m), and $\mathrm{Z} 05(600 \mathrm{~m})$. The lower values from the current observational dataset came from the Barrow measurements and are most comparable to those obtained by M07 and S08a from the same time period. Cloud thickness estimates derived here (mean 210-650 m) fall in line with those from Z05 (450 m), P98 (100-300 m), S08a (400$700 \mathrm{~m}$ ), and M07 (500 m). However, they are less thick than those derived in S06 (1000-2500 m) because in that study the definition of "cloud" included both the mixedphase layer and ice precipitation below, adding significantly to cloud depth. Both data here and from S06 indicate correlation between cloud thickness and season. Both show thicker clouds in late summer, fall, and early winter and thinner clouds in late winter, spring, and early summer. This may be associated with a seasonal cycle of moisture available for cloud formation. During the latter months, the ocean is covered by sea ice and less moisture is available to the atmosphere.

Another hint at a relationship between cloud thickness and moisture availability can be found in wind direction estimates. Sea ice maxima during spring reduce moisture sources to the north and east of Eureka. However, relatively warm conditions with open ocean waters persist around southern Greenland. As mentioned previously, both spring and summer reveal a preference for mixedphase clouds to develop under southerly wind directions.

Cloud optical depths were reviewed in T05, with derived values ranging from 0 to 6 (limit for instrumentation). Within this distribution, there appears to be a relatively flat distribution of occurrences between ODs of approximately 0.5 and 5 and fewer occurrences of ODs above 5. This is comparable to data from the current study, which show seasonal variation in mean OD IQRs ranging between 0.75 and 5 (again, instrument limited). Figure 4 reveals that most Barrow clouds and many of those observed in Eureka were thicker than $\mathrm{OD}=5$. 
Temperatures observed during the current study (242-271 K) also match well with those from previous work. S06 revealed seasonal mean in-cloud temperatures ranging from $\sim 248$ to $263 \mathrm{~K}$. S08a found cloud-top temperatures between 255 and $269 \mathrm{~K}$ for MPACE, with the majority of those values falling between 257 and $266 \mathrm{~K}$. Our analysis from MPACE reveals a slightly colder range of temperatures, between 250 and $260 \mathrm{~K}$. M07 studied a significantly shorter case period than the present study, but their findings fall within the ranges covered here (cloud-top temperature range of 257-269 K, with the peak of the distribution around $261 \mathrm{~K}$ ).

Liquid particle effective diameters, which here had seasonally dependent mean values of $12-47 \mu \mathrm{m}$, are slightly larger than estimates of M07 (13-27 $\mu \mathrm{m}, 18-22 \mu \mathrm{m}$ means), and T05 (5-40 $\mu \mathrm{m}$, distribution peak at $14 \mu \mathrm{m})$. Again, this is most likely due to the retrieval method employed sampling both liquid and ice simultaneously. Although the contribution from the ice is small, it is significant enough to bias the estimates.

Liquid droplet number density estimates vary over orders of magnitude between different studies. For example, M07 found values ranging from $10^{4}$ to $10^{5} \mathrm{~L}^{-1}$ (mean values between 2.3 and $7.2 \times 10^{4} \mathrm{~L}^{-1}$ ), whereas Z05 reported mean values of approximately $2 \times 10^{5} \mathrm{~L}^{-1}$. Both of these estimates were derived from Forward Scattering Spectrometer Probes (FSSPs). With some exceptions (August 2005, MAM 2006, SON 2006, JJA 2007), seasonal mean lidar-radar estimates are generally comparable to those from M07 but slightly lower than Z05 estimates, falling between $3 \times 10^{4}$ and $2.6 \times$ $10^{5} \mathrm{~L}^{-1}$. Z05 measurements were made during the typically polluted Arctic spring. Interestingly, Eureka data do not show clear increases in spring liquid number densities. This is possibly due to a combination of factors, including retrieval errors, geographic location, and observation frequency. First, MAM 2006 does appear to have higher liquid particle numbers than the surrounding seasons. MAM 2007 does not and exhibits higher radar-derived IWC estimates. The increased ice amount would contaminate liquid retrievals as previously discussed, resulting in underprediction of liquid concentrations. In addition, the MAM 2007 sample size was small, with only $30.5 \mathrm{~h}$ of observations during this 3 -month period. Because this limited sample size is due in part to instrument failures (Fig. 2), it is likely that clouds were missed, resulting in an unrepresentative dataset. Finally, it is speculated that Eureka's northerly location $\left(80^{\circ}\right)$ and distance from Asian pollution sources limit pollution influence on cloud properties when compared to regions over the Beaufort Sea, for example.

For subcloud ice particle concentrations, M07 observed values between 1 and $17 \mathrm{~L}^{-1}$ (mean values of
1.6-5.6 $\mathrm{L}^{-1}$ ) for particles larger than $53 \mu \mathrm{m}$, comparing very well with the majority of data points from the current study. These number density comparisons are very rough, however, because of the limited number of cases covered by M07 and Z05 when compared with the multiyear dataset from Eureka.

Mean in situ LWC estimates from M07 ranged between 0.15 and $0.19 \mathrm{~g} \mathrm{~m}^{-3}$, whereas Z05 measured LWC to range from around $0.01 \mathrm{~g} \mathrm{~m}^{-3}$ near cloud base to $0.06 \mathrm{~g} \mathrm{~m}^{-3}$ near cloud top using the FSSP and King in situ probes. $\mathrm{P} 98$ also utilized the King probe and showed LWC to range from 0.008 to $0.02 \mathrm{~g} \mathrm{~m}^{-3}$ at cloud base to around $0.1 \mathrm{~g} \mathrm{~m}^{-3}$ at cloud top. Sampling mainly the bottom and center sections of clouds, lidar-radarretrieved mean LWC estimates of $0.06-0.28 \mathrm{~g} \mathrm{~m}^{-3}$ seem to fall in line with previous estimates. The upper end of this range occurred in Barrow cases, which match very well with M07's estimates from the same location and time period. Despite these similarities, lidar-radar retrievals did present estimates of up to $0.7 \mathrm{~g} \mathrm{~m}^{-3}$, which is higher than observed in previous studies. Mean IWC estimates from M07 ranged from 0.006 to $0.03 \mathrm{~g} \mathrm{~m}^{-3}$, typically increasing from cloud top to cloud base but remaining constant below cloud base. P98 and Z05 showed similar spatial distributions, with IWC estimates ranging from 0.001 to $0.06 \mathrm{~g} \mathrm{~m}^{-3}$ and 0.001 to $0.02 \mathrm{~g} \mathrm{~m}^{-3}$, respectively. All of these in situ measurements fall within the range of retrieved values from the present dataset. S08a's estimated mean IWC of $0.023 \mathrm{~g} \mathrm{~m}^{-3}$ for MPACE clouds is slightly lower than the currently presented estimated mean for the same time period $\left(\sim 0.04 \mathrm{~g} \mathrm{~m}^{-3}\right)$.

LWPs derived during SHEBA in S06 had a mean of $61 \mathrm{~g} \mathrm{~m}^{-2}$ and ranged from 2.2 to $180 \mathrm{~g} \mathrm{~m}^{-2}$, whereas LWP derived during MPACE in S08a had a mean of $156 \mathrm{~g} \mathrm{~m}^{-2}$ while ranging from 27 to $310 \mathrm{~g} \mathrm{~m}^{-2}$. Z05 presented LWP estimates ranging from near zero to $120 \mathrm{~g} \mathrm{~m}^{-2}$. Generally, LWP estimates from the current work fit into the ranges presented. As discussed previously, Barrow LWPs were significantly higher, matching observations by S08a. Higher mean LWP reported in S08a is likely due to the inclusion of additional cases featuring layered clouds, or during which the lidar was inoperative.

Previous studies have attempted to derive a relationship between liquid water fraction (LWF) and temperature for these clouds. This relationship would aid in proper division of phase in numerically simulated clouds. Using in situ measurements of LWC and IWC, M07 show an average increase in LWF with decreasing temperature over a range of $257-273 \mathrm{~K}$. This occurs because cloud top is typically coldest and has the largest LWC and smallest IWC. Unlike M07 LWF estimates, the S06 and S08a studies use vertically integrated LWP and IWP 
to derive LWF. S06 shows a steep decrease in LWF with decreasing temperature, with average LWFs near zero at temperatures as warm as $257 \mathrm{~K}$. S08a reveals a distribution of estimates where nearly $95 \%$ of LWF values are greater than $50 \%$ due to large LWPs observed during MPACE. Unfortunately, the use of vertically integrated quantities requires inclusion of subcloud ice in liquid water fraction calculations, making them less representative of the ice partition within the mixed-phase layer.

Results from the current study are shown in Fig. 11 and are divided into cases from Barrow (stars) and $\mathrm{Eu}-$ reka (circles). Here, LWF is defined as

$$
\mathrm{LWF}=\frac{\langle\mathrm{TWC}\rangle-\langle\mathrm{IWC}\rangle}{\langle\mathrm{TWC}\rangle},
$$

where $\langle\mathrm{TWC}\rangle$ and $\langle\mathrm{IWC}\rangle$ are the mean lidar-radarderived water content and radar-derived ice water content within the mixed-phase region, respectively. Although not defined in exactly the same manner, LWF derived here is most similar to that used in S06 and S08a. Unlike in those studies, however, this approach limits LWF estimates to the mixed-phase region and does not include ice contributions from subcloud precipitation. As discussed earlier, $\langle\mathrm{TWC}\rangle$ values are likely too high within the cloud layer because of the bimodal distribution of particle sizes. This causes the LWF estimate to be slightly too high. However, because $\langle\mathrm{TWC}\rangle$ is used in both numerator and denominator, even errors in $\langle\mathrm{TWC}\rangle$ of $50 \%$ would only result in a LWF error of $\sim 25 \%$, which translated to data from this study results in changes of LWF between 0.07 and 0.22 .

All cases have relatively high LWFs, with values ranging between approximately $65 \%-100 \%$, and the majority of values are above $85 \%$, similar to S08a. Looking at the entire dataset, values higher than $85 \%$ occur across the observed temperature range (242-273 K), and there is a trend toward lower values of LWF as temperature decreases. Inclusion of points not measured because of lidar attenuation would likely increase LWF estimates, since cloud top has greater LWC and lower IWC (M07). Based on large discrepancies between estimates of LWF from different studies, it is not surprising that parameterized phase partitioning in numerically simulated mixed-phase clouds has proven challenging.

\section{b. Differences between Barrow and Eureka}

This section briefly compares properties of clouds observed at Barrow to those observed at Eureka during fall in order to analyze location-dependent cloud characteristics. Although fall exhibits the most frequent occurrence of single-layer mixed-phase stratiform clouds at both Barrow and Eureka, they occurred nearly twice as frequently in

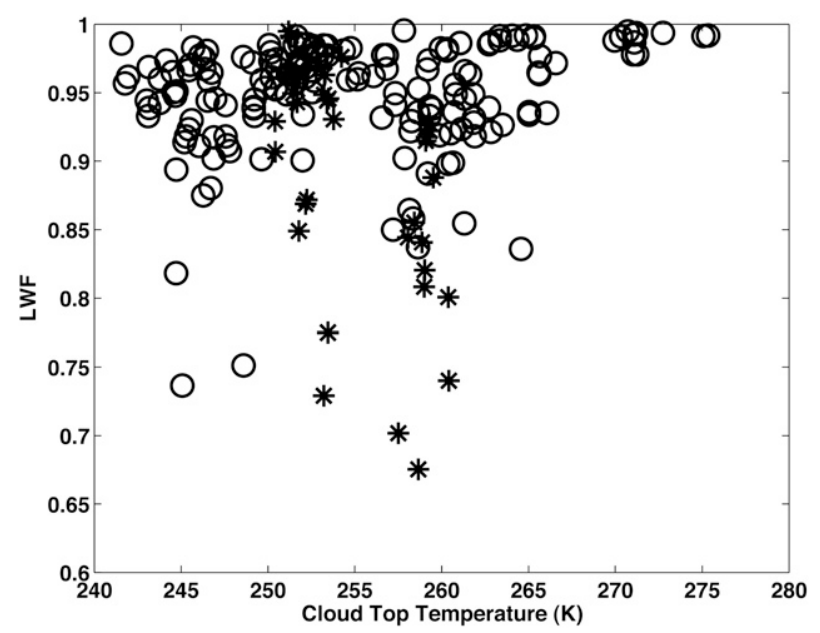

FIG. 11. Liquid water fraction [(TWC - IWC)/TWC] vs cloudtop temperature for cases observed in Barrow (stars) and Eureka (circles).

Barrow. Barrow clouds typically have lower cloud bases and are significantly thicker both optically and physically. The temperature range of fall mixed-phase cloud occurrence is similar for both locations ( $\sim 245-260 \mathrm{~K})$.

Microphysical quantities also show differences between the two locations. Barrow has significantly larger IWCs. These larger IWCs contaminate retrieved estimates of in-cloud TWC (higher), liquid number density (lower), and liquid particle effective size (larger). It is unproven that the above relationships are solely due to ice-induced retrieval errors, but comparison with in situ observations of M07 (de Boer et al. 2008) appears to indicate that this is likely the case. Comparing subcloud ice number densities, retrieved properties from Barrow are very similar to those from Eureka, while ice particle size, and thereby IWC estimates are larger. These larger ice particles are not surprising, as thicker Barrow clouds would result in more time spent inside the saturated mixed-phase region for ice particles.

These observations indicate that there may be significant differences between mechanisms driving Barrow clouds versus those in Eureka. Many clouds observed at Barrow during fall 2004 resulted from a "cold-air outbreak" situation, with northeast winds bringing air from the sea ice pack over the open Beaufort Sea (Verlinde et al. 2007). The boundary layer was convective, and sea surface heat and moisture fluxes were significant. Satellite observations from MPACE show roll structures similar to those commonly observed over the Great Lakes in fall and early winter. In contrast, many clouds in Eureka appear to form independently of the boundary layer, with cloud-top radiative cooling driving buoyancy circulations that support cloud maintenance (Herman 
and Goody 1976). These eddies are not necessarily driven by surface energy fluxes, allowing Eureka clouds to be detached from local sources of buoyancy and moisture.

\section{Conclusions}

Arctic mixed-phase clouds occur frequently. Proper representation of these clouds remains a challenging problem for modelers, in part because of a general dearth of observations. In this work, a multiyear dataset is presented utilizing measurements from lidar, radar, MWR, and radiosondes. This dataset contains information on mean macro- and microphysical characteristics specifically focused on single-layer mixed-phase stratiform clouds. In addition, comparison between measurements at several Arctic locations is provided. This is done directly between measurements from Eureka, Canada, and Barrow, Alaska, as well as indirectly with results from previous studies at various locations.

It remains true that full characterization of these clouds is not possible at this time (Shupe et al. 2008b). In particular, bimodal particle size distributions inside the mixedphase cloud layer provide a challenging environment for many retrieval algorithms. The extent and impact of uncertainties in the data and retrieval methods are presented throughout this manuscript. The most notable uncertainties lie in the characterization of liquid droplet size.

A summary of mean macro- and microphysical properties for these clouds, along with key findings, is presented below. Again, mean values reported here exclude outliers as previously described.

- Single-layer mixed-phase clouds occurred with a frequency of $26 \%$ (of total time observed, cloudy and clear conditions) at Barrow during fall of 2004 and a mean frequency of $8 \%$ at Eureka. Multilayer cases are not included here, and there were significant variations in frequency by season.

- Fall clouds observed at Barrow had a mean cloud-base height of $688 \mathrm{~m}$, mean thickness of $650 \mathrm{~m}$, and occurred at temperatures between 249 and $263 \mathrm{~K}$.

- Fall Barrow clouds had a mean retrieved effective diameter of $47 \mu \mathrm{m}$, likely due largely to ice contamination of the lidar-radar retrieval. The mean retrieved number density was $2.8 \times 10^{4} \mathrm{~L}^{-1}$, mean retrieved TWC was $0.28 \mathrm{~g} \mathrm{~m}^{-3}$, mean retrieved IWC was $0.04 \mathrm{~g} \mathrm{~m}^{-3}$, and mean retrieved LWP was $106 \mathrm{~g} \mathrm{~m}^{-2}$.

- Precipitation from the clouds observed at Barrow had a mean retrieved effective diameter of $123 \mu \mathrm{m}$, mean retrieved number density of $16 \mathrm{~L}^{-1}$, and mean retrieved IWC of $0.03 \mathrm{~g} \mathrm{~m}^{-3}$.

- Clouds observed at Eureka had a mean cloud-base altitude of $1720 \mathrm{~m}$, mean thickness of $338 \mathrm{~m}$, and occurred at temperatures between 240 and $272 \mathrm{~K}$.

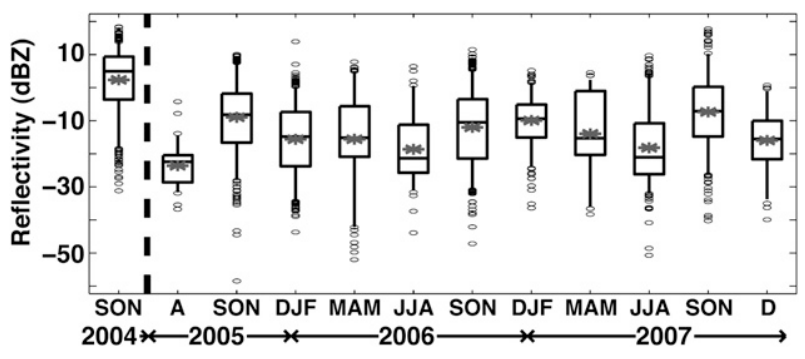

FIG. 12. Seasonal statistics of mean maximum (within the vertical column) in-cloud radar reflectivity as measured by the MMCR for single-layer mixed-phase clouds as observed at Barrow (2004) and Eureka (2005-07). The box-and-whisker plots are as in Fig. 5.

- Eureka clouds had a mean retrieved effective diameter of $24 \mu \mathrm{m}$, mean retrieved number density of $8.6 \times$ $10^{4} \mathrm{~L}^{-1}$, mean retrieved TWC of $0.09 \mathrm{~g} \mathrm{~m}^{-3}$, mean retrieved IWC of $0.004 \mathrm{~g} \mathrm{~m}^{-3}$, and mean retrieved LWP of $38 \mathrm{~g} \mathrm{~m}^{-2}$.

- Precipitation from clouds observed at Eureka had a mean retrieved effective diameter of $93 \mu \mathrm{m}$, mean retrieved number density of $9 \mathrm{~L}^{-1}$, and mean retrieved IWC of $0.006 \mathrm{~g} \mathrm{~m}^{-3}$.

- Liquid fraction is shown to decrease with decreasing temperature.

- Seasonal mean LWCs and IWCs appear to change in phase with one another; Seasons with high LWCs also had higher IWCs.

- Barrow clouds typically are lower and thicker, with higher water contents than those found at Eureka.

It is hoped that data from this study will be used to improve detection and simulation of mixed-phase stratiform clouds. Many satellite platforms depend on a priori information about clouds to aid in their detection. Properties such as cloud altitude, temperature, optical depth, and physical thickness can aid in correct detection of specific cloud types. Additionally, this information can be utilized to assess whether specific instruments can detect these clouds at all. CloudSat, for example, has been shown to have difficulties with mixed-phase cloud recognition and evaluation (de Boer et al. 2008). Part of this is likely due to the fact that some of these clouds do not have sufficient ice to be detected by CloudSat. Figure 12 shows seasonal mean maximum radar reflectivities detected by the MMCR in the current study. CloudSat is able to detect to approximately $-29 \mathrm{dBZ}$. Additional sources of complication for CloudSat measurements come from low cloud altitudes and thicknesses. CloudSat has a vertical resolution of $500 \mathrm{~m}$, and ground clutter is an issue for signals detected within the lowest two range gates. Of 3012 cases analyzed in the present study, 206 had mean maximum radar reflectivities under $-29 \mathrm{~dB} Z$ and 316 had cloud-top altitudes under $1000 \mathrm{~m}$. 
In addition to advances in cloud detection and observation, information presented here can aid in improvement of mixed-phase cloud parameterizations for numerical models. S06 give a brief overview of model parameterizations, including temperature limits presented by Ose (1993), Del Genio et al. (1996), Tiedtke (1993), Smith (1990), and others. Lower temperature ranges for mixed-phase cloud occurrence from these parameterizations range from 233 to $264 \mathrm{~K}$. In this work, it was shown that mixed-phase clouds readily exist at temperatures down to $240 \mathrm{~K}$, and that there is a general (but not robust) decrease in liquid fraction with decreasing temperature. Additionally, cloud frequencies and altitudes presented here can be compared with results from large-scale model predictions.

Improved analysis of the mixed-phase layer must continue to be pursued. Improved retrieval methods, potentially utilizing particle fall velocities and information from additional instruments such as microwave radiometers and interferometers, could aid in better characterization of cloud liquid. In particular, separation of liquid and ice contributions to the lidar and radar signals would help to reduce ambiguity in the measurements. Additionally, improved spatial coverage through additional long-term observational sites as well as satellite measurements will aid in improving our understanding of differences observed in cloud properties among different Arctic locations. New active remote sensing platforms with improved measurement capabilities are being developed and will aid in future findings about these clouds. Finally, focused studies such as the recently completed Indirect and Semi-Direct Aerosol Campaign (ISDAC; Ghan et al. 2008) will help to provide high-resolution information useful for understanding the processes responsible for the occurrence of these cloud structures.

Acknowledgments. The authors acknowledge Joseph Garcia for work on the database from which this information was gathered. Additionally, thanks to Igor Razenkov, Ralph Kuehn, and Jim Hedrick for work on the AHSRL. Funding for this effort came from multiple funding sources, including NASA (NNX07AQ81G), the DOE ARM program (ER64187-1027586-0011923 and DE-FG02-05ER63965), NSF (ARC0632187), and NOAA. Comments from Dr. Jennifer Kay and two anonymous reviewers significantly improved the content of this work.

\section{REFERENCES}

Alley, R., and Coauthors, 2007: Summary for policy makers. Climate Change 2007: The Physical Science Basis, S. Solomon et al., Eds., Cambridge University Press, 1-18.
Curry, J. A., and E. E. Ebert, 1992: Annual cycle of radiation fluxes over the Arctic Ocean: Sensitivity to cloud optical properties. J. Climate, 5, 1267-1280.

— W. B. Rossow, D. Randall, and J. L. Schramm, 1996: Overview of Arctic cloud and radiation characteristics. J. Climate, 9, 1731-1764.

de Boer, G., G. J. Tripoli, and E. W. Eloranta, 2008: Preliminary comparison of CloudSAT-derived microphysical quantities with ground-based measurements for mixed-phase cloud research in the Arctic. J. Geophys. Res., 113, D00A06, doi:10.1029/ 2008JD010029.

Deirmendjian, D., 1969: Electromagnetic Scattering on Spherical Polydispersions. Elsevier, 290 pp.

Del Genio, A. D., M.-S. Yao, W. Kovari, and K. K.-W. Lo, 1996: A prognostic cloud water parameterization for global climate models. J. Climate, 9, 270-304.

Donovan, D. P., and A. C. A. P. van Lammeren, 2001: Cloud effective particle size and water content profile retrievals using combined lidar and radar observations. 1 . Theory and examples. J. Geophys. Res., 106, 27 425-27 448.

Eloranta, E. W., 2005: High spectral resolution lidar. RangeResolved Optical Remote Sensing of the Atmosphere, K. Weitkamp, Ed., Springer-Verlag, 143-163.

Ghan, S., and Coauthors, 2008: Indirect and Semi-Direct Aerosol Campaign (ISDAC). DOE Office of Science, Atmospheric Radiation Measurement Program, 23 pp. [Available online at http://www.asp.bnl.gov/ARM_ISDAC.pdf.]

Herman, G., and R. Goody, 1976: Formation and persistence of summertime Arctic clouds. J. Atmos. Sci., 33, 1537-1553.

Klein, S. A., and Coauthors, 2009: Intercomparison of model simulations of mixed-phase clouds observed during the ARM Mixed-Phase Arctic Cloud Experiment. Part I: Single-layer cloud. Quart. J. Roy. Meteor. Soc., 135, 979-1002.

Korolev, A. V., G. A. Isaac, and J. Hallett, 1999: Ice particle habits in Arctic clouds. Geophys. Res. Lett., 26, 1299-1302.

Matrosov, S. Y., 1999: Retrievals of vertical profiles of ice cloud microphysics from radar and IR measurements using tuned regressions between reflectivity and cloud parameters. J. Geophys. Res., 104, 16 741-16 753.

McFarquhar, G. M., G. Zhang, M. R. Poellot, G. L. Kok, R. McCoy, T. Tooman, A. Fridlind, and A. J. Heymsfield, 2007: Ice properties of single-layer stratocumulus during the MixedPhase Arctic Cloud Experiment: 1. Observations. J. Geophys. Res., 112, D24201, doi:10.1029/2007JD008633.

Mitchell, D. L., 1996: Use of mass- and area-dimensional power laws for determining precipitation particle terminal velocities. J. Atmos. Sci., 53, 1710-1723.

Moran, K. P., B. E. Martner, M. J. Post, R. A. Kropfli, D. C. Welsh, and K. B. Widener, 1998: An unattended cloud-profiling radar for use in climate research. Bull. Amer. Meteor. Soc., 79, 443-455.

Morison, J., 2001: SEARCH: Study of Environmental Arctic Change: Science Plan, 2001. SEARCH Project Office, 89 pp. [Available online at http://www.arcus.org/search/resources/ files/SEARCH_Science_Plan.pdf.]

Morrison, H., and Coauthors, 2009: Intercomparison of model simulations of mixed-phase clouds Observed during the ARM Mixed-Phase Arctic Cloud Experiment. Part II: Multi-layered cloud. Quart. J. Roy. Meteor. Soc., 135, 1003-1019.

Ose, T., 1993: An examination of the effects of explicit cloud water in the UCLA GCM. J. Meteor. Soc. Japan, 71, 93-109.

Pinto, J. O., 1998: Autumnal mixed-phase cloudy boundary layers in the Arctic. J. Atmos. Sci., 55, 2016-2038. 
Pruppacher, H. R., and J. D. Klett, 1997: Microphysics of Clouds and Precipitation. 2nd ed. Kluwer Academic, 954 pp.

Rogers, D. C., P. J. DeMott, and S. M. Kreidenweis, 2001: Airborne measurements of tropospheric ice-nucleating aerosol particles in the Arctic spring. J. Geophys. Res., 106, 15 053-15 063.

Shupe, M. D., and J. M. Intrieri, 2004: Cloud radiative forcing of the Arctic surface: The influence of cloud properties, surface albedo, and solar zenith angle. J. Climate, 17, 616-628.

_ - T. Uttal, and S. Y. Matrosov, 2005: Arctic cloud microphysics retrievals from surface-based remote sensors at SHEBA J. Appl. Meteor., 44, 1544-1562.

_, S. Y. Matrosov, and T. Uttal, 2006: Arctic mixed-phase cloud properties derived from surface-based sensors at SHEBA J. Atmos. Sci., 63, 697-711.

_ , P. Kollias, P. O. G. Persson, and G. M. McFarquhar, 2008a: Vertical motions in Arctic mixed-phase stratiform clouds. J. Atmos. Sci., 65, 1304-1322.

_ - and Coauthors, 2008b: A focus on mixed-phase clouds: The status of ground-based observational methods. Bull. Amer Meteor. Soc., 89, 1549-1562.
Smith, R. N. B., 1990: A scheme for predicting layer clouds and their water content in a general circulation model. Quart. J. Roy. Meteor. Soc., 116, 435-460.

Tiedtke, M., 1993: Representation of clouds in large-scale models. Mon. Wea. Rev., 121, 3040-3061.

Turner, D. D., 2005: Arctic mixed-phase cloud properties from AERI lidar observations: Algorithm and results from SHEBA. J. Appl. Meteor., 44, 427-444.

— S. A. Clough, J. C. Liljegren, E. E. Clothiaux, K. Cady-Pereira, and K. L. Gaustad, 2007: Retrieving liquid water path and precipitable water vapor from the Atmospheric Radiation Measurement (ARM) microwave radiometers. IEEE Trans. Geosci. Remote Sens., 45, 3680-3690.

Uttal, T., and Coauthors, 2002: Surface heat budget of the Arctic Ocean. Bull. Amer. Meteor. Soc., 83, 255-275.

Verlinde, J., and Coauthors, 2007: The Mixed-Phase Arctic Cloud Experiment. Bull. Amer. Meteor. Soc., 88, 205-221.

Zuidema, P., and Coauthors, 2005: An Arctic springtime mixedphase cloudy boundary layer observed during SHEBA. J. Atmos. Sci., 62, 160-176. 